OPEN ACCESS

Edited by:

Diana Deca

Technical University Munich, Germany

*Correspondence: Brett Buttliere, brettbuttliere@gmail.com

Received: 17 April 2015 Accepted: 24 April 2015 Published: 08 May 2015

Citation:

Buttliere B (2015) Corrigendum: Using Science and Psychology to improve the dissemination and evaluation of scientific work.

Front. Comput. Neurosci. 9:53. doi: 10.3389/fncom.2015.00053

\section{Corrigendum: Using Science and Psychology to improve the dissemination and evaluation of scientific work}

\section{Brett Buttliere}

Net-based Knowledge Communication in Groups, Knowledge Media Research Center, Tübingen, Germany

Keywords: science, open science, open data, using science to improve science, behavioral economics, psychology

\section{A corrigendum on}

Using science and psychology to improve the dissemination and evaluation of scientific work by Buttliere BT (2014). Front. Comput. Neurosci. 8:82. doi: 10.3389/fncom.2014.00082

The citation of Hartgerink (2014)

"Open science protocol," in Poster Presented at the Annual Meeting of the Society for Personality and Social Psychology (San Antonio, Texas, US)

should instead be a citation to Bik and Goldstein (2013)

Bik, H. M., and Goldstein, M. C. (2013). An introduction to social media for scientists. PLoS Biol. 11(4), e1001535. doi: 10.1371/journal.pbio.1001535

Conflict of Interest Statement: The author declares that the research was conducted in the absence of any commercial or financial relationships that could be construed as a potential conflict of interest.

Copyright $\odot 2015$ Buttliere. This is an open-access article distributed under the terms of the Creative Commons Attribution License (CC BY). The use, distribution or reproduction in other forums is permitted, provided the original author(s) or licensor are credited and that the original publication in this journal is cited, in accordance with accepted academic practice. No use, distribution or reproduction is permitted which does not comply with these terms. 